\title{
MEMRECS-A Sustainable View for Metal Recycling from Waste Printed Circuit Boards
}

\author{
Hoang-Long Le*, Eiji Yamasue, Hideyuki Okumura, Keiichi N. Ishihara
}

Graduate School of Energy Science, Kyoto University, Kyoto, Japan.

Email: *lehoanglong.inest@gmail.com

Received May $11^{\text {th }}, 2013$; revised June $12^{\text {th }}, 2013$; accepted June $19^{\text {th }}, 2013$

Copyright (c) 2013 Hoang-Long Le et al. This is an open access article distributed under the Creative Commons Attribution License, which permits unrestricted use, distribution, and reproduction in any medium, provided the original work is properly cited.

\begin{abstract}
This study analyses the metal recyclability from waste Printed Circuit Boards (PCBs) with three material recycling quoting approaches: Material Recycling Efficiency (MRE), Resource Recovery Efficiency (RRE), and Quotes for Environmentally Weighted Recyclability (QWERTY). The results indicate that MRE is likely inapplicable to quoting the metal recyclability of waste PCBs because it makes the recycling of any metal equal to each other (e.g. recycling of 1 $\mathrm{kg}$ of gold is as important as recycling of $1 \mathrm{~kg}$ of iron). RRE and QWERTY can overcome the poor yardstick of MRE because they concern not only the weight of recycled materials but also the contribution of recycled materials to the natural resource conservation and the environmental impact reduction, respectively. These two approaches, however, report an extremely different result, that makes the target stakeholders get confused with which material recycled. From the findings of the aforementioned analysis, this study proposes the Model for Evaluating Metal Recycling Efficiency from Complex Scraps (MEMRECS) as a new approach to quotes the metal recycling performance. MEMRECS allows the trade-offs between three criteria: mass, environmental impacts and natural resources conservation, hence it can provide the result in a sustainable sound manner. MEMRECS clearly models and enhances the role of natural resources conservation aspect rather than QWERTY does.
\end{abstract}

Keywords: PCBs; Environmental Impacts; Natural Resources Conservation; Metal Recyclability

\section{Introduction}

Metals have been playing as an indispensable role in the development of human society, as P. Laznicka, 2010 [1] mentioned that metals are one category of a trio of geological materials on which is based our present industrial civilization. The other two categories are mineral fuels like coal, petroleum and natural gas, and nonmetallic like stone, sand and gravel, salt or clays. Unlike other materials, metals are not biodegradable and have virtually an unlimited lifespan and the potential for unlimited recyclability. Hence they are well suited for sustainable development goals [2]. If appropriately managed, recycling metal can provide numerous benefits for the environment in terms of energy savings, reduced volumes of waste, and reduced greenhouse gas emissions associated with energy savings. For example, the amount of energy saved using various recycled metals compared to virgin ore is up to $95 \%$ for aluminum [3], $85 \%$ for copper [4], 60 percent for steel [5], $75 \%$ for zinc [3], and $90 \%$ for nickel

*Corresponding author.
[6]. Metal recycling also conserves natural resources by reducing the amount of virgin ore needed to be mined, as well as other resources. For instance, recycling one ton of steel conserves 1.13 tons of iron ore, 0.64 ton of coal and 0.05 ton of limestone. Recycling a ton of aluminum conserves up to 8 tons of bauxite ore [7].

As a matter of fact, the recovery of valuable metals from waste PCBs is an attractive business recently since PCBs typically contain about $40 \%$ of metals [8] with a wide range of elements from precious metals (e.g. gold, silver, palladium, platinum), rare metals (e.g. beryllium, indium), base metals (e.g. copper, aluminum, nickel, tin, zinc, iron), and toxic heavy metals (e.g. lead, cadmium, antimony). Each metal element contained in PCBs has its own specific properties according to different points of view such as weight content, economic value, environmental impacts, natural resources depletion, etc. Hence, each of metal fractions will have different share of the total metal recyclability of product. Ideally, if all metal fractions of waste PCBs were recovered with $100 \%$ recovery rate, the metal recyclability would always be full 
score (100\%), irrespective of how much individual metal fractions contribute to total metal recyclability of product (further called "contribution score"). However, in reality it can never be achieved due to the limitations of technology, economy, only several metal fractions are preferred to the task of recovery. Therefore, in order to optimize the recyclability of a product, it is necessary to understand the contribution score of every individual metal fraction contained in this product.

This study analyses the contribution score of metal fractions contained in three types of PCB with three different material recycling quoting (MRQ) approaches: Material Recycling Efficiency (MRE) [9], Resource Recovery Efficiency (RRE) [10], and Quotes for environmentally Weighted RecyclabiliTY (QWERTY) [11]. Furthermore, this study also proposes the so called MEMRECS (Model for Evaluating Metal Recyclability from Complex Scraps) [12] as a new approach to quotes the metal recycling performance in sustainable sound manner. The contribution scores are then presented by MEMRECS approach and compared with previous approaches.

\section{Contribution Score for Waste PCBs with Different MRQ Approaches}

\subsection{Material Quoting Approaches}

Although the choice on the proper scientific method of measurement may be subject to debate, the most common way of determining the recyclability of products is material recycling efficiency (MRE) - the amount of material per product that may be recycled, when the product reaches the end of its useful life [9]. In other words, it can be defined as Equation (1). $E_{i}$ is specific recovery rate of material $i, W_{i}$ is amount of material $i$ contained in product.

$$
M R E=\sum_{i} E_{i} \times W_{i}
$$

When dealing with the resource conservation issue, Legarth et al. (1995) [10] proposed a quantitative measure which states resource recovery in terms of one number: The resource recovery efficiency (RRE) defined as Equation (2). $F_{i}$ is the amount of material $i$ in one ton of product, $P_{i}$ is annual production of of the resource $i, C_{i}$ is annual consumption of the resource $i, R_{i}$ is the world reserves of the resource $i$, and $E_{i}$ is specific recovery rate of material $i$.

$$
R R E=\sum_{i} E_{i} \times \frac{F_{i}}{P_{i}} \times \frac{C_{i}}{R_{i}} \approx \sum_{i} E_{i} \times \frac{F_{i}}{R_{i}}
$$

Life cycle assessment (LCA) is a standard approach for environmental impact evaluation [11]. Based on LCA data, Huisman et al., 2003 [13] developed QWERTY concept for calculating product recyclability on a real environmental basis defined as Equation (3). $E V W_{\text {actual, }}$ is the defined actual environmental impact for the weight of material i. $E V W_{\text {max }, i}$ is the defined maximum environmental impact for the weight of material i. $E V W_{\min }$ and $E V W_{\text {max }}$ are total defined minimum and maximum environmental impact for the complete product, respectively.

$$
Q W E R T Y=\sum_{i} \frac{E V W_{\text {actual }, i}-E V W_{\max , i}}{E V W_{\min }-E V W_{\max }}
$$

\subsection{Data Sources}

- PCBs samples are collected at a scrap village located in Vinh Phuc province of Vietnam. At laboratory, each PCBs sample is cut and ground to powder with particle size under $1000 \mu \mathrm{m}$ by a laboratory cutting mill Retsch SM 2000. Powder product is then dissolved with aqua regia in solid liquid ratio of 1:20 (1 $\mathrm{g}$ of sample to $20 \mathrm{ml}$ of aqua regia solution). The contact time between the fraction samples and aqua regia is about 24 hours at room temperature to ensure complete digestion of metals; followed by filtration with quantitative filter paper $[14,15]$. The leached portion is then made up to $500 \mathrm{ml}$ by adding deionized water before analyzing the metal content by inductively couple plasma mass spectrometry (ICP-MS). The metal composition of PCBs samples is shown in Ta-

\begin{tabular}{|c|c|c|c|c|c|c|}
\hline & \multicolumn{2}{|c|}{ CRT TV } & \multicolumn{2}{|c|}{ Desktop PC } & \multicolumn{2}{|c|}{ Cell phone } \\
\hline & a & $\mathrm{b}$ & a & $\mathrm{b}$ & a & c \\
\hline Weight (g/unit) & 745.33 & - & 444.65 & - & 14.70 & - \\
\hline $\mathrm{Al}(\mathrm{wt} \%)$ & 11.98 & 10 & 3.93 & 5 & 0.96 & 0.99 \\
\hline $\mathrm{Fe}(\mathrm{wt} \%)$ & 11.41 & 28 & 7.68 & 7 & 10.79 & 6.53 \\
\hline Co (wt\%) & 0.002 & - & 0.001 & - & 0.17 & - \\
\hline Ni (wt\%) & 0.22 & 0.3 & 0.24 & 1 & 1.73 & 1.67 \\
\hline $\mathrm{Cu}(\mathrm{wt} \%)$ & 11.79 & 10 & 25.50 & 20 & 38.87 & 38.33 \\
\hline $\mathrm{Zn}(\mathrm{wt} \%)$ & 1.25 & - & 5.07 & - & 0.33 & 0.97 \\
\hline $\mathrm{Pb}(\mathrm{wt} \%)$ & 2.68 & 1 & 1.77 & 1.5 & 1.67 & 1.26 \\
\hline Sn (wt\%) & 3.19 & 1.4 & 4.42 & 2.9 & 2.49 & 3.11 \\
\hline $\mathrm{Sb}(\mathrm{wt} \%)$ & 0.016 & - & 0.10 & - & 0.04 & - \\
\hline $\mathrm{Au} / \mathrm{ppm}$ & 7 & 17 & 82 & 250 & 1645 & 1000 \\
\hline $\mathrm{Pd} / \mathrm{ppm}$ & 20 & 10 & 22 & 110 & 142 & - \\
\hline Ag/ppm & 49 & 280 & 274 & 1000 & 3985 & 600 \\
\hline $\begin{array}{c}\text { Non-metal } \\
\text { (wt/\%) }\end{array}$ & 57.46 & - & 51.24 & - & 42.37 & - \\
\hline
\end{tabular}
ble 1.

Table 1. Material composition of waste PCBs.

a This study; ${ }^{\mathrm{b} C h r i s t i a n ~ H a g e l u k e n, ~} 2006$ [16]; ' Angela C. Kasper et al., 2011 [17]. 
- Environmental values are constructed by LCA software Simapro PhD version 7.2 using Eco-indicator'99 (H/A) [18] as scoring indicator. Inventory database is derived from Eco-invent version 2.1 specified for the Boliden Rönnskär copper smelter in Sweden [19], one of the world's most efficient copper smelters and a world-leader in the recycling of copper and precious metals from electronic scrap. In addition, the calculation of environmental values is based on an assumption that starting point for calculation is the moment PCBs scraps are fed into the process, which means environmental burden of previous steps such as collection, dismantling, transportation is excluded from the calculation.

- The world reserves of metals are referred from Mineral commodity summaries 2012 [20].

\subsection{Results}

Figures 1-3 present the contribution scores of three types

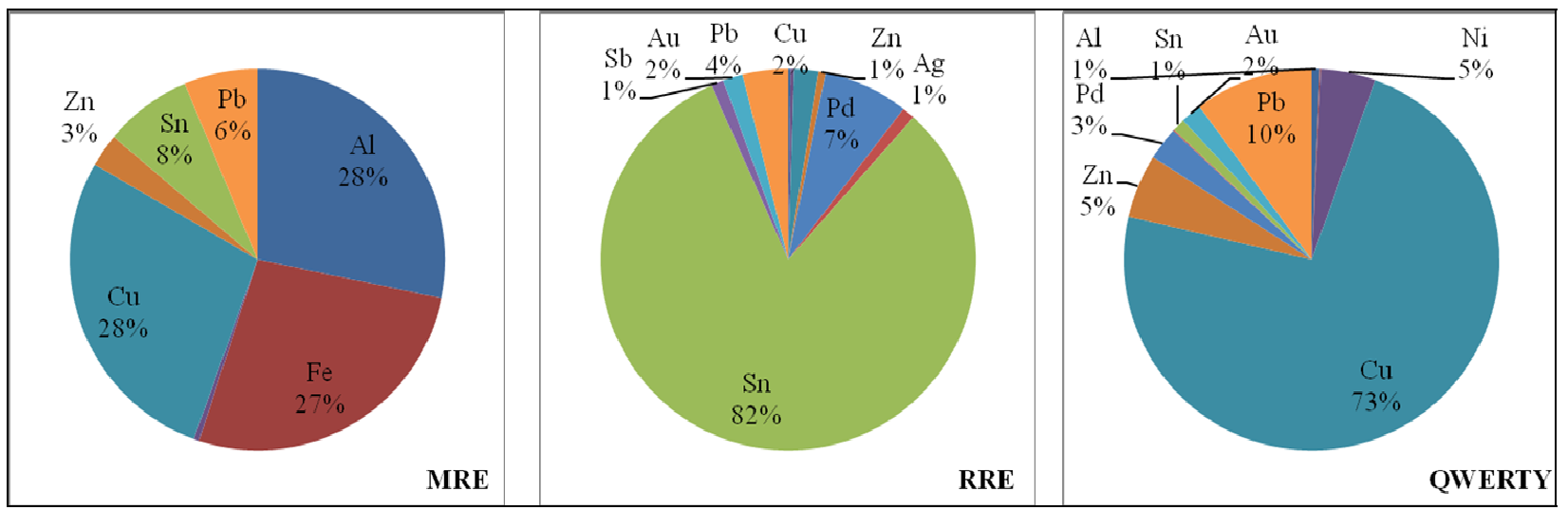

Figure 1. The contribution scores for CRT TV' PCB with different MRQ approaches.

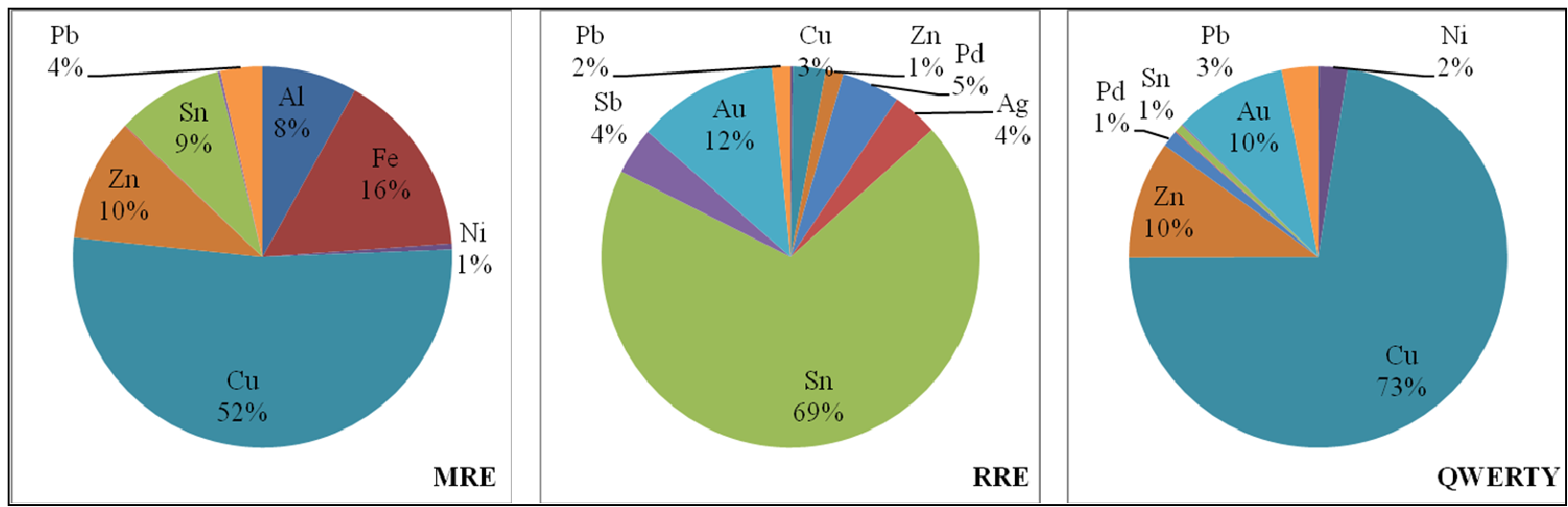

Figure 2. The contribution scores for Desktop PC' PCB with different MRQ approaches.

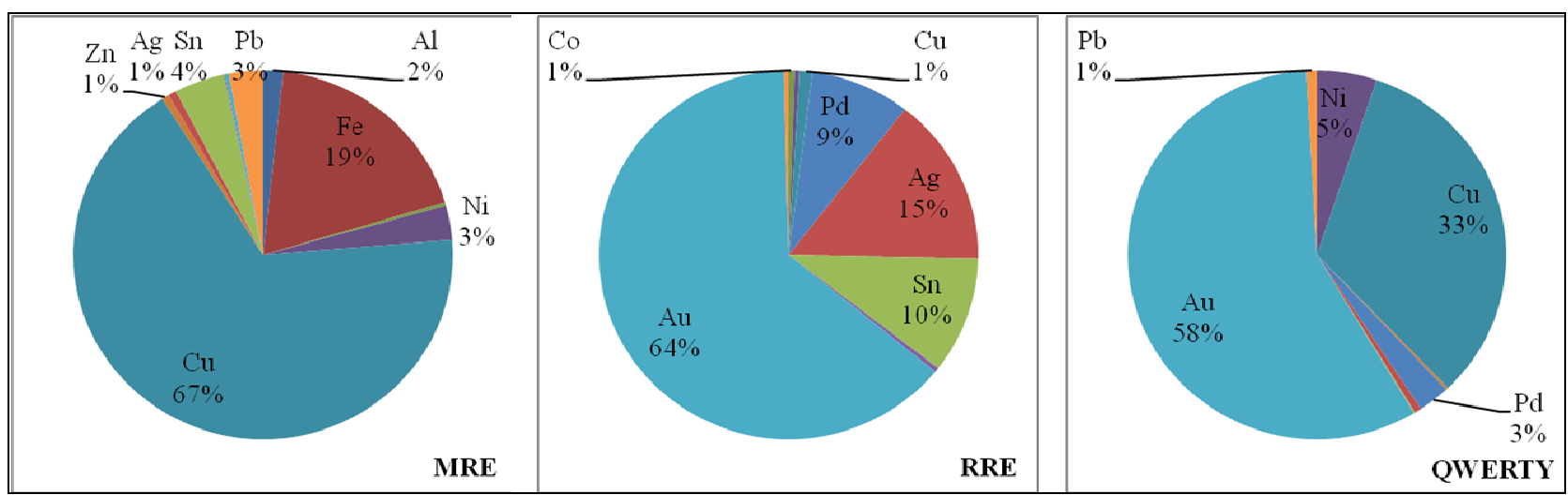

Figure 3. The contribution scores for Cell phone’ PCB with different MRQ approaches. 
of PCB according to aforementioned MRQ approaches. Obviously that MRE approach only focuses on the weight of recyclable parts. Metal fractions with high weight content such as copper, iron, aluminum therefore have high contribution score, without concerning about the other impacts of materials to environment, economic, resource conservation etc.

According to RRE approach, the weight dominant fractions such as copper, iron and aluminum have negligible contribution score to total metal recyclability of waste PCBs. Tin fraction makes up only less than $10 \%$ in weight base, but it becomes the highest contribution score in case of PCB from CRT TV and Desktop PC. It also considerably contributes to the total metal recyclability of PCB from Cell phone. Interestingly, the minor weight fractions like precious metals (gold, silver, palladium) become significant contribution scores.

In terms of QWERTY approach, among the weight dominant fractions, iron and aluminum also have almost no contribution to the total metal recyclability of PCBs. On the other hands, copper fraction is found as the most dominant contribution score with respect to the PCBs from CRT TV and Desktop PC. Lead and zinc fractions also have considerable contribution scores. Despite of extremely low weight content, gold fraction still have remarkable contribution score for PCB from Desktop PC, and it has the highest value of contribution score for PCB from Cell phone.

In summary, the pie charts showing the relative contribution scores to the total recyclability of waste PCBs reported by MRE, RRE and QWERTY are substantially different from each other. The problem of MRE is that it concerns about weight only, thus it can make the recovery of $1 \mathrm{~kg}$ of iron or any different materials from a counterweight of product as important as recovering $1 \mathrm{~kg}$ of gold. It is irrational to the sense of nature. The aim of MRE approach is clearly to reduce amount of waste in terms of quantitative terms rather than recovering really valuable materials, it is therefore suitable to measure the metal recyclability of product that contains single metal fraction such as waste steel from demolition, copper wires scrap, aluminum cans, where no competition between various metal fractions. RRE and QWERTY approaches can overcome the solely weight base problem of MRE since they are assessing not only the weight of metal fractions but also the contribution of every metal fraction to specific evaluation aspect (natural resources conservation in RRE or environmental impact in QWERTY). However, they report an extremely different result, making the target stakeholders get confused with which material recycled. For these notions, it would be desirable to develop an inclusive measure, which compromises the contribution scores associated with each of three points of view mentioned above.

\section{Proposing MEMRECS Approach}

As analyzed in Section 2, the contribution score of several metal fractions contained in PCBs such as $\mathrm{Cu}, \mathrm{Sn}, \mathrm{Fe}$, $\mathrm{Al}, \mathrm{Zn}, \mathrm{Pb}, \mathrm{Au}, \mathrm{Ag}, \mathrm{Pd}$ is highly changed with different MRQ approaches. If followed one of these approaches to set the priority for the recovery of metal from waste PCBs, it might lead to over or underestimation with which metal fraction recovered. For example, in the case of CRT TV' PCB, if following MRE approach, copper, iron and aluminum are preferred for recovery. That will lead to the loss of benefit from natural resources conservation point of view which is embedded in tin fraction and the benefit from environmental impact which is hidden in lead fraction. If following RRE approach, tin fraction will be the main target to be recovered. In this case, the environmental benefit from copper fraction will be sacrificed. Conversely, if following QWERTY approach, benefit of natural resources conservation from tin fraction will be lost.

This notion has led to the development of the Model for Evaluating Metal Recycling Efficiency for Complex Scraps (MEMRECS) as a new approach to quote the metal recyclability of scraps containing various metal fractions in general and waste PCBs in particular. With the aim of evaluating metal recyclability in sustainable sound manner, MEMRECS not only include the weight of each metal fraction but also comprise two critical aspects associated with sustainable issue: natural resources conservation and environmental impact reduction. In other worlds, MEMRECS is a combination of MRE, RRE and QWERTY.

\subsection{Construction of MEMRECS}

In general, given a complex scrap with $m$ metal fractions, metal recyclability according to a certain aspect $j$ can be expressed by Equation (4). Whereas, $E_{i}$ is the recovery rate of metal fraction $i, M_{i}$ is the metric weight of metal faction $i, w_{i j}$ is weighting factor of metal faction $i$ according to evaluation aspect $j$.

$$
M R_{j}=\sum_{i=1}^{m} E_{i} \frac{M_{i} w_{i j}}{\sum_{i=1}^{m} M_{i} w_{i j}}, i \in[1 . . m], j \in[1 . . n]
$$

Basically, MEMRECS is the solution of a multicriteria problem, in which two fundamental viewpoints including natural resources conservation and environmental impacts are taken into account simultaneously. Hence, the task now is finding the way to combine the weighting factors representative for these two points of view into only one composite weighting factor $w_{i, \text { comp }}$ representative for composite viewpoint. Then, the metal recyclability according to MEMRECS approach can be expressed by Equation (5). Whereas, $w_{i, \text { comp }}$ is the weighting factor 
of metal fraction $i$ according to composite viewpoint

$$
\text { MEMRECS }=\sum_{i=1}^{m} E_{i} \frac{M_{i} w_{i, \text { comp }}}{\sum_{i=1}^{m} M_{i} w_{i, \text { comp }}}
$$

\subsection{Combination of Weighting Factors Using Entropy Weighting Method}

In multicriteria problems, it is reasonable to assign a weight to each criterion in order to represent the relative importance of criterion against each others. There are many techniques to elicit the weights, such as the weighted evaluation technique, the eigenvector method, the analytic hierarchy process (AHP) method, the weighted least square method and so forth [21]. However, most of them entail subjectivity in assigning weights to criteria due to using opinion of experts, and because of that, there is no guarantee that these weights will be replicated when another person or team estimates them [22] In order to guarantee the consistency of the model, this study employs Entropy weighting method - an objective weighting method [23] to elicit the weights of evaluation criteria. The calculation steps are as following as in [21]:

A multicriteria decision making problem with $m$ alternative and $n$ criteria can be expressed in decision matrix as Equation (6).

$$
D=\left(x_{i j}\right)_{m \times n}, i \in[1 . . m], j \in[1 . . n]
$$

A normalized decision matrix representing the relative performance of the alternatives is obtained as Equation (7).

$$
P=\left(p_{i j}\right)_{m \times n}, i \in[1 . . m], j \in[1 . . n]
$$

where

$$
P_{i j}=x_{i j} / \sum_{i=1}^{m} x_{i j}
$$

The amount of decision information contained in Equation (7) and emitted from each criterion can be measured by entropy value as Equation (8).

$$
e_{j}=-\frac{1}{\ln (m)} \sum_{i=1}^{m} p_{i j} \ln \left(p_{i j}\right), i \in[1 . . m], j \in[1 . . n]
$$

The degree of diversity of the information contained by each criterion can be calculated as Equation (9).

$$
d_{j}=1-e_{j}, j \in[1 . . n]
$$

Then, the weight or relative importance for each criterion is given by Equation (10).

$$
I_{j}=\frac{d_{j}}{\sum_{j=1}^{n} d_{j}}, j \in[1 . . n]
$$

Finally, the composite weight representative for general viewpoint for metal fraction $i$ is generated by Equation (11).

$$
w_{i, \text { comp }}=\sum_{j} I_{j} w_{i j}, j \in[1 . . n]
$$

\subsection{Calculation of MEMRECS}

With the general idea and combination method described above, the four steps for calculating MEMRECS can be expressed as follows:

- First step, compute the weighting factors of all metal fractions according to the natural resource conservation aspect $\left(w_{i, R C}\right)$, and environmental impact aspect $\left(w_{i, E I}\right)$. Base on the RRE concept and QWERTY concept, the $w_{i, R C}, w_{i, E I}$ are calculated by Equation (12) and Equation (13), respectively.

$$
w_{i, R C}=\frac{\frac{1}{R_{i}}}{\sum_{i} \frac{1}{R_{i}}}
$$

Whereas:

o $R_{i}$ is the world reserves estimated in the year of calculation of metal element $i$

$$
w_{i, E I}=\frac{E V_{i, a c t u a l}-E V_{i, \max }}{\sum_{i} E V_{i, \text { min }}-E V_{i, \text { max }}}
$$

Whereas:

o $E V_{i, \min }$ is the minimum environmental impact value to recover metal element $i$ in its initial grade without any environmental burden of treatment steps. In other words, it is the environmental substitution value for the extraction of raw material for metal element $i$.

o $E V_{i, \max }$ is the maximum environmental impact value for metal element $i$ in the worst end-of-life case.

o $E V_{i, \text { actual }}$ is the environmental impact value to recover metal element $i$ in actual case.

- Second step, compute the relative criteria importance using Entropy method with $p_{i j}$ is substituted by $w_{i j}$.

- Third step, compute composite weight for each metal fraction by Equation (11).

- Fourth step, compute MEMRECS score by Equation (5).

An important note: in some cases, the resource depletion impact has been also included in QWERTY through life cycle impact assessment (LCIA) models. For these cases, only score on environmental impacts is used in the calculation of $w_{i, E I}$, in order to avoid overlapping the evaluation of resource conservation aspect. 


\section{Contribution Score for Waste PCBs with MEMRECS Approach}

MEMRECS is calculated with the same data sources described in the Section 2.2. However, instead of using whole score of Eco-indicator'99, only score on damage to ecosystems and damage to human health is put into the calculation in order to avoid overlapping evaluation since the damage to resources depletion is also integrated in eco-indicator'99. The relative contribution scores of metal fractions contained in waste PCBs are shown in Figure 4. It indicates that the result of MEMRECS is a compromise between the results of RRE and QWERTY. It is a common sense because MEMRECS allows tradeoffs between criteria. A poor score in RRE can be negated by a good score in QWERTY and reversely. According to MEMRECS, copper and tin fractions are the main contributors. They make up about $70 \%-80 \%$ of the total metal recyclability of PCBs from CRT TV and Desktop PC. For PCB from Cell phone, gold is the most important contributor which shares $60 \%$ total metal recyclability, irrespective of its small weight content. Copper is also a significant contributor, which shares $22 \%$ total metal recyclability.

In general, in order to optimize the efficiency of metal recycling from PCBs in the context that are not all metal fractions can be recovered, a priority should be given to the metal fractions that have high contribution score. Table 2 is the summaries of the metal fractions that are preferred for the recovery from waste PCBs with respect to different MRQ approaches. It is easy to find that the preferred metal fractions according to MEMRECS mostly are the preferred metal fractions according to both RRE and QWERTY. If the target is simply qualitative determination of which metal fractions should be recovered to optimize the recycling efficiency of metal from waste PCBs in the sustainable sound manner, selecting the preferred metal fractions according to both RRE and QWERTY is probably enough. However, the advantage of MEMRECS is that it is not only qualitatively identifying the preferred metal fractions but also quantitatively calculating the contribution score of every metal fraction.

\section{MEMRECS versus QWERTY Expressed with Eco-Indicator'99}

QWERTY is calculated with environmental values, those derived from any LCIA models. Depending on LCIA model, the environmental value expresses the environmental impacts only, or expresses both environmental impacts and resource depletion impact. The Eco-indicator'99 is a comprehensive method, in which resource depletion impact has been considered as one of environmental impact. Thus, the QWERTY expressed with Ecoindicator'99 (QWERTY/Eco-indicator'99) seems to be similar to MEMRECS in terms of approaching ideal. It is notably valuable to discuss the difference between MEMERCS and QWERTY/Eco-indicator'99.

As shown in Table 3, the difference between two models occurs in three viewpoints. The first one is the unit or the way expressing the resource depletion impact. QWERTY/Eco-indicator'99 does not consider the quantity of resources, but rather the resource quality. The resource aspect is modeled via the term "surplus energy", which describes energy requirements for future mining will increase due to decreasing mineral ore concentration. The nature sense of surplus energy actually is energy consumption that finally reflects the environmental impacts rather than saving natural resources. In contrast, the resources depletion impact in MEMRECS is derived from RRE, which describes the times of natural resources can be saved by recycling based on the resource quantity. By this way, the resource depletion impact is considered more clearly and closely to the resource depletion issue in the true sense of word. Thus, MEMRECS enhances the role of resource conservation rather than that of QWERTY/Eco-indicator'99. It is demonstrated by the contribution score of tin fraction.
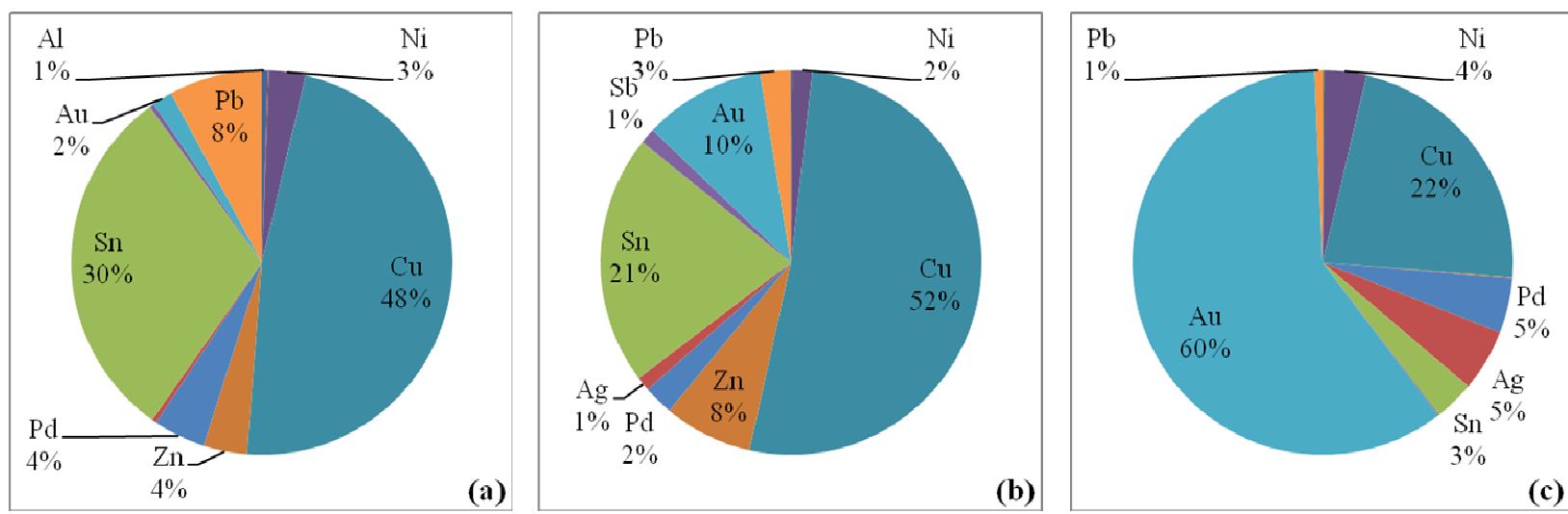

Figure 4. The contribution scores for different types of PCB according to MEMRECS approaches ((a) PCB from CRT TV; (b) PCB from Desktop PC; (c) PCB from Cell phone). 
Table 2. Metal recovery priority for PCBs according to different MRQ approaches.

\begin{tabular}{cccc}
\hline & CRT TV & Desktop PC & Cell phone \\
& PCB & PCB & PCB \\
\hline MRE & $\mathrm{Cu}, \mathrm{Al}, \mathrm{Fe}$ & $\mathrm{Cu}, \mathrm{Fe}, \mathrm{Zn}$ & $\mathrm{Cu}, \mathrm{Fe}$ \\
RRE & $\mathrm{Sn}, \mathrm{Pd}$ & $\mathrm{Sn}, \mathrm{Au}$ & $\mathrm{Au}, \mathrm{Ag}, \mathrm{Sn}, \mathrm{Pd}$ \\
QWERTY & $\mathrm{Cu}, \mathrm{Pb}$ & $\mathrm{Au}, \mathrm{Cu}$ & $\mathrm{Au}, \mathrm{Cu}$ \\
MEMRECS & $\mathrm{Cu}, \mathrm{Sn}, \mathrm{Pb}$ & $\mathrm{Cu}, \mathrm{Sn}, \mathrm{Au}$ & $\mathrm{Au}, \mathrm{Cu}, \mathrm{Ag}, \mathrm{Pd}$ \\
\hline
\end{tabular}

Table 3. The difference between QWERTY/Eco-indicator'99 and MEMRECS in terms of modeling the resource conservation aspect.

\begin{tabular}{|c|c|c|}
\hline & QWERTY/Eco-indicator’99 & MEMRECS \\
\hline Unit & $\begin{array}{l}\text { “Surplus energy” in MJ per kg } \\
\text { extracted material }\end{array}$ & $\begin{array}{c}\text { The times natural } \\
\text { resource can be saved } \\
\text { by recycling }\end{array}$ \\
\hline $\begin{array}{l}\text { Weighting } \\
\text { method }\end{array}$ & Expert panel group method & $\begin{array}{l}\text { Entropy weighting } \\
\text { method }\end{array}$ \\
\hline Data source & Until 1990 & Recent mining data \\
\hline
\end{tabular}

The second point is weighting method to elicit the relative importance of criteria or criteria weights. In QWERTY/Eco-indicator'99, the criteria weights are determined by expert panel group method based on the opinion of group of experts or stakeholders. In this way, the relative importance of environmental damage and resources damage is subjectively fixed as 0.8 and 0.2 , respectively [24]. In MEMRECS, the relative importance objective weighting method, which determines criteria weights based on intrinsic information of each evaluation criterion. Obviously, the difference in weighting method point of view also makes the resources conservation aspect in MEMRECS is appreciated rather than that in QWERTY/Eco-indicator'99.

The third point is the data sources used to model the resource depletion impact. As mentioned, the resource depletion impact in QWERTY/Eco-indicator'99 is modeled base on surplus energy. On the other hand, the estimated ore grade corresponding to a cumulative extraction value equal to five times the 1980 level is used to estimate the surplus energy [25]. It is clear that the choice of five times is arbitrary and the data sources in 1980 are outdated, which probably makes the estimation contain considerable uncertainties. In MEMRECS, the data source for modeling the resource depletion impact via RRE is derived from Mineral commodity summaries 2012-a recent mining data, and such data source is annually updated. Thus the result of MEMRECS also can never be outdated, and it will reflect resource depletion issue to a higher degree than QWERTY/Eco-indicator' 99 does.

\section{Conclusions}

In this study, MEMRECS has been introduced as a new quantitative measure for quoting the metal recyclability of waste PCBs. MEMRECS can provide insights into the contribution of every metal fraction to the total metal recyclability of waste PCBs, on the condition that both environmental impact and natural resources conservation aspects are considered simultaneously, which will be really helpful for setting the priority in metal recovery, according to both qualitative and quantitative forms.

The comparison between MEMRECS and QWERTY/ Eco-indicator'99 is also implemented in this study. The analysis results indicate that natural resources conservation aspect in MEMRECS is considered more clearly and directly than that in QWERTY/Eco-indicator'99. Furthermore, MEMRECS enhances the role of resource conservation aspect other than QWERTY/Ecoindicator'99 does.

With its own properties, MEMRECS is probably applicable in setting the benchmark for metal recycling strategy, and it is also helpful in technological selection or technological improvement for metal recycling from waste PCBs in particular and scraps containing various metal fractions in general.

\section{Acknowledgements}

This work was partly supported by an "Energy Science in the Age of Global Warming" of Global Center of Excellence (G-COE) program (J-051) of the Ministry of Education, Culture, Sports, Science and Technology of Japan.

\section{REFERENCES}

[1] P. Laznicka, “Giant Metallic Deposits,” 2nd Edition, Springer-Verlag, Berlin Heidelberg, 2010. doi:10.1007/978-3-642-12405-1_1

[2] T. E. Norgate and W. J. Rankin, "The Role of Metals in Sustainable Development”.

http://www.minerals.csiro.au/sd/CSIRO_Paper_LCA_Sus t.pdf

[3] K. J. Martchk, "The Importance of Recycling to the Environmental Profile of Metal Products," Proceedings of the 4th International Symposium on Recycling of Metals and Engineered Materials, 2000, pp. 19-28.

[4] http://en.wikipedia.org/wiki/Scrap

[5] http://green.wikia.com/wiki/Metal_recycling

[6] H. H. Kellogg, "Sizing up The Energy Requirements for Producing Primary Metals,” Engineering \& Mining Journal, Vol. 187, No. 4, 1977, pp. 61-65.

[7] http://environment.about.com/od/recycling/a/metal-recycl ing.htm

[8] M. P. Luda, "Recycling of Printed Circuit Boards,” In: S. Kumar, Ed., Integrated Waste Management-Volume II, r InTech, New York, 2011, pp. 285-299. http://cdn.intechopen.com/pdfs/18491/InTech-Recycling_ 
of_printed_circuit_boards.pdf

[9] H. Kalimo, "E-Cycling: Linking Trade and Environmental Law in the EC and the US," Transnational Publishers, Inc., Ardsley, 2006, pp. 251-262.

[10] J. B. Legarth, L. Alting and G. L. Baldo, "Sustainability Issues in Circuit Board Recycling," Proceedings of the 1995 IEEE International Symposium on Electronics and the Environment, Orlando, 1-3 May 1995, pp. 126-131.

[11] J. Li, P. Shrivastava, Z. Gao and H. C. Zhang, "Printed Circuit Board Recycling: A State-of-the-Art Survey," IEEE Transactions on Electronics Packaging Manufacturing, Vol. 27, No. 1, 2004, pp. 33-42. doi:10.1109/TEPM.2004.830501

[12] H. L. Le, K. N. Ishihara, E. Yamasue and H. Okumura, "Assessment of Metal Recovery Efficiency for Waste Printed Circuit Boards in Vietnam with MEMRECS and Different End-of-Life Scenarios,” The 28th International Conference on Solid Waste Technology and Management, 10-13 March 2013, pp. 123-132.

[13] J. Huisman, C. B. Boks and A. L. N. Stevels, "Quotes for Environmental Weighted Recyclability-The Concept of Describing Product Recyclability in Terms of Environmental Value," International Journal of Production Research, Vol. 41, No. 16, 2003, pp. 3649-3665. doi:10.1080/0020754031000120069

[14] Y. J. Park and D. J. Fray, "Recovery of High Purity Precious Metals from Printed Circuit Boards," Journal of Hazardous Materials, Vol. 164, No. 2-3, 2009, pp. 11521158. doi:10.1016/j.jhazmat.2008.09.043

[15] L. H. Yamane, V. T. Moraes, D. C. R. Espinosa and J. A. S. Tenorio, "Recycling of WEEE: Characterization of Spent Printed Circuit Boards from Mobile Phones and Computers,” Waste Management, Vol. 31, No. 12, 2011, pp. 2553-2558. doi:10.1016/j.wasman.2011.07.006

[16] C. Hageluken, "Improving Metal Returns and Eco-Efficiency in Electronic Recycling-A Holistic Approach for Interface Optimization between Pre-Processing and Integrated Metals Smelting and Refining," Proceedings of the 2006 IEEE International Symposium on Electronic and the Environment, 8-11 May 2006, pp. 218-223.

[17] A. C. Kasper, G. B. T. Berselli, B. D. Freitas, J. A. S. Tenório, A. M. Bernardes and H. M. Veit, "Printed Wiring Boards for Mobile Phones: Characterization and Recycling of Copper,” Waste Management, Vol. 31, No. 12, 2011, pp. 2536-2545.

[18] M. Classen, H. J. Althaus, S. Blaser, M. Tuchschmid, N. Jungbluth, G. Doka, M. Faist Emmenegger and W. Scharnhorst, "Life Cycle Inventories of Metals. Final Report Ecoinvent Data v2.1,” EMPA Dübendorf. Swiss Centre for Life Cycle Inventories, Dubendorf, 2009.

[19] M. Goedkoop and R. Spriensma, “The Eco Indicator’99, a Damage-Oriented Method for Life Cycle Impact Assessment. Final Report,” National Reuse of Waste Research Program, Pré Consultants, Amersfoort, 2000.

[20] “Mineral Commodity Summaries 2012,” US Geological survey, Reston, 2012.

[21] J. Huang, "Combining Entropy Weight and TOPSIS Method for Information System Selection,” International Conference on Cybernetics and Intelligent Systems, Qingdao, 1-3 September 2008, pp. 1281-1284.

[22] N. Munier, “A Strategy for Using Multicriteria Analysis in Decision-Making," Springer Science + Business Media B.V., Dordrecht, 2011, p. 45.

[23] J. C. Pomerol and S. B. Romero, "Multicriterion Decision in Management: Principles and Practice," Kluwer Academic Publisher, Norwel, 2000, pp. 87-89. doi:10.1007/978-1-4615-4459-3

[24] R. Frischknecht and N. Jungbluth, "Implementation of Life Cycle Impact Assessment Methods,” Ecoinvent Report No. 3, Dübendorf, 2007, p. 46.

[25] P. Swart and J. Dewulf, "Quantifying the Impacts of Primary Metal Resource Use in Life Cycle Assessment Based on Recent Mining Data," Resources, Conservation and Recycling, Vol. 73, 2013, pp. 180-187. doi:10.1016/j.resconrec.2013.02.007 